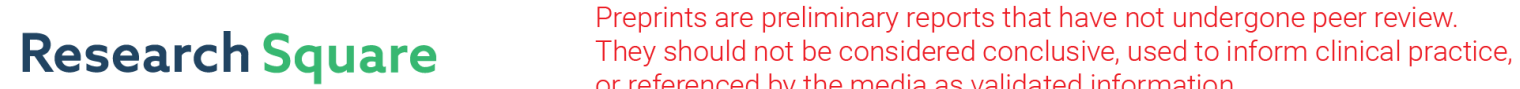 or referenced by the media as validated information. \\ Durable and High-efficiency Casein-derived Phosphorus-nitrogen-rich Flame Retardants for Cotton Fabrics
}

\section{Fang Xu}

Southwest University

Guangxian Zhang ( $\square$ zgx656472@sina.com.cn )

College of Textiles and Garments, Southwest University, Chongqing https://orcid.org/0000-0002-62179216

\section{Peng Wang}

Southwest University

\section{Fangyin Dai}

Southwest University

\section{Research Article}

Keywords: cotton fabrics, casein, bio-based flame retardants, durability

Posted Date: September 21st, 2021

DOl: https://doi.org/10.21203/rs.3.rs-884727/v1

License: (c) (i) This work is licensed under a Creative Commons Attribution 4.0 International License. Read Full License

Version of Record: A version of this preprint was published at Cellulose on January 21st, 2022. See the published version at https://doi.org/10.1007/s10570-022-04430-y. 


\section{Abstract}

A casein derivative (CADP) was synthesized using casein, which is bifunctional containing both $-\mathrm{P}=\mathrm{O}\left(\mathrm{O}^{-}\right.$ $\left.\mathrm{NH}_{4}{ }^{+}\right)_{2}$ reactive groups and $-\mathrm{P}(=0)$-O-C- groups, and the durable flame-retardant cotton fabrics were successfully prepared by CADP. The $-\mathrm{P}=\mathrm{O}\left(\mathrm{O}^{-} \mathrm{NH}_{4}{ }^{+}\right)_{2}$ reactive groups allowed CADP to be firmly grafted onto cellulose. The $-P(=0)-0-C$ - groups made flame-retardant cotton fabrics more resistant to soaping and improved its durability. The modification by $40 \%$ CADP increased the limited oxygen index value (LOI) of cotton fabric from $17.4 \%$ to $41.6 \%$, which maintained at $26.4 \%$ after 50 cycles of home machine washes. The results of TG, TG-FTIR and SEM indicated that CADP increased the condensed components and decreased the flammable gaseous compounds, resulting the positive effect on char formation of cellulose. The whiteness and tensile strength of cotton fabrics were retained well after modification, and the treated cotton fabrics didn't have skin irritation.

\section{Introduction}

Among all nature textile, cotton fabric is generally applied to clothing, furnishing, automobile, industry and other fields, because of the advantages of good wearability, comfort and dyeability, etc (Sun et al., 2021; Pei, Gu \& Wang, 2021). However, cotton fabric is highly flammable, which poses a threat to human beings and limits its applications (Xie, Gao \& Zhang, 2013; Feng et al., 2017). So, the flame-retardant modification is necessary for cotton fabrics.

Over the past years, various flame retardants have been developed to modify the flammability of cotton fabrics, including halogen-containing, phosphorus-containing (Liu, Chen \& Wang, 2012), nitrogencontaining (Xu et al., 2018), sulfur-containing (Xu, Wang \& Yu, 2017), boric-containing (Luo et al., 2020), metal hydroxides (Wang et al., 2020), intumescent flame retardants (Wang, Ma, Liu, Tian \& Fu, 2021), and so on. Among them, the most commonly studied flame retardants are phosphoruscontaining/phosphorus-nitrogen-containing flame retardants, because they are low toxicity, high efficiency and less smoke produced in the combustion process (Zhang, Jiang, Zhu \& Zhu, 2021). At present, Pyrovatex $\mathrm{CP} \circledast$ and Proban ${ }^{\circledR}$ are widely used as commercial products for the modification of cotton, because they are very efficient and durable (Poon \& Kan, 2015; Mohamed \& Abdel-Mohdy, 2006; Yang, Wang, Lei, Fei \& Xin, 2012). However, they have the problem of formaldehyde release (Yasin, Behary, Curti \& Rovero, 2016; Horrocks, 2011). Up to now, the flame retardants for cotton fabrics can not meet the requirements of halogen-free, formaldehyde-free, efficient and durable.

As the shortage of oil becoming a global issue, the application of renewable resources has been paid more and more attention. It was considered a promising strategic approach to use different biomass materials to improve the flame retardant property of cotton fabrics, such as nucleic acids (DNAs), plant extracts and proteins (Salmeia, Gaan \& Malucelli, 2016; Basak \& Ali, 2016; Malucelli et al., 2014). By layerby-layer method or exhaust method, some plant extracts (banana pseudostem and spinach juice) have been used as flame retardants for cotton, because they contain small amounts of phosphorus and metal oxides. These plant extracts could increase the limiting oxygen index ( $\mathrm{LOI})$ values of cotton fabrics to 
30\% (Basak et al., 2015; Basak, Samanta \& Chattopadhyay, 2015). DNA contains phosphate groups, deoxyribose units and nitrogen-containing bases, which has been investigated as a natural intumescent flame retardant for textiles (Isarov et al., 2016; Alongi et al., 2014a; Alongi et al., 2013a; Alongi et al., 2015; Carosio, Blasio, Alongi \& Malucelli, 2013). It was found that DNA increased the LOl values of cotton fabrics to $28 \%$ by layer-by-layer (Alongi et al., 2013b; Bosco et al., 2015). DNA can form phosphoric acid to have the positive effect on char formation and inhibit the continuous combustion of cellulose, but DNA can not be applied on a large scale. Some $\mathrm{P}-\mathrm{N}$ - and S-rich proteins like caseins, whey proteins and hydrophobins were also used as "green" flame retardants for textiles (Bosco et a., 2013; Alongi et al., 2014b; Carosio, Blasio, Cuttica, Alongi, \& Malucelli, 2014; Faheem, Baheti, Tunak, Wiener \& Militky, 2019). By deposition method, these proteins could be homogeneously coated on cotton fabrics, the burning rate of treated fabric was decreased. These biomass materials are widely existing in the nature of various plants and animals, with safe, non-toxic and environmental-friendly characteristics. However, the cotton fabrics treated with these biomass materials have poor flame retardant property and durability, and they can not meet the commercial requirements.

In our previous work, $-\mathrm{P}=\mathrm{O}\left(\mathrm{O}^{-} \mathrm{NH}_{4}^{+}\right)_{2}$ reactive groups have been introduced into amino acids and proteolytic amino acids, to develop efficient and durable bio-based flame retardants (Xu et al., 2019a; Xu et al., 2019c). From the results, $-\mathrm{P}=\mathrm{O}\left(\mathrm{O}^{-} \mathrm{NH}_{4}{ }^{+}\right)_{2}$ reactive groups reacted with the $-\mathrm{OH}$ of cellulose to generate $\mathrm{P}(=0)-0-\mathrm{C}$ groups, and increased the binding between the flame retardants and cellulose (Liu et al., 2021; Xu et al., 2019b; Jia, Lu, Zhang, Liang \& Zhang, 2017; Chen, Wan, Liu, Wang \& Zhang, 2021). These bio-based $\mathrm{P}$ - and $\mathrm{N}$-rich flame retardants could significantly increase the LOI values of cotton fabrics to $40 \%$. Because the covalent bonds between flame retardants and cellulose, the flame retardant property of treated cotton fabrics was durable, which could withstand 50 laundering cycles (LCs) of careful hand washes. However, the flame retardant property was greatly reduced after home machine washes. The unreacted $-\mathrm{P}=\mathrm{O}\left(\mathrm{O}^{-} \mathrm{NH}_{4}{ }^{+}\right)_{2}$ groups on treated cotton fabrics would react with the metal ions during washing process, leading to a considerable reduction of the flame retardant property.

In this current study, a casein derivative (CADP) was synthesized using casein, which is bifunctional containing both $-\mathrm{P}=\mathrm{O}\left(\mathrm{O}^{-} \mathrm{NH}_{4}{ }^{+}\right)_{2}$ reactive groups and $-\mathrm{P}(=\mathrm{O})$-O-C- groups. And the durable flame-retardant cotton fabrics were successfully prepared. On the one hand, the reaction between $-\mathrm{P}=\mathrm{O}\left(\mathrm{O}^{-} \mathrm{NH}_{4}{ }^{+}\right)_{2}$ groups and cellulose during modification can make CADP graft onto the cellulose. On the other hand, the $-P(=0)$ O-C- groups could reduce the effect of soaping solution on the flame retardant property of cotton fabrics and improved their durability. The flame retardant property, flame retardant mechanisms, thermal decomposition, whiteness, tensile properties and skin irritation of cotton fabrics were studied.

\section{Experimental}

Materials 
Pure cotton fabrics $\left(134.2 \mathrm{~g} / \mathrm{m}^{2}\right)$ were purchased from the market. Casein, phosphorous acid $\left(\mathrm{H}_{3} \mathrm{PO}_{3}\right)$, dimethyl phosphite, dicyandiamide, hydrochloric acid ( $37 \% \mathrm{w} / \mathrm{w})$, urea, sodium hydroxide, ammonia solution ( $25 \% \mathrm{w} / \mathrm{w}$ ) and 2-propanol were supplied by Kelong Chemical Reagent Co., Ltd. (Chengdu, China). Formaldehyde (37\% w/w) were purchased from Boyi Chemical Reagent Co., Ltd. (Chongqing, China). The without optical brightener (WOB) standard reference detergent was supplied by Dongguan Xudong Instrument Co., Ltd. (Dongguan, China). All chemicals were of reagent grade.

Preparation of flame retardants

First, $22.00 \mathrm{~g}$ of casein, $11.00 \mathrm{~g}(0.1 \mathrm{~mol})$ of dimethyl phosphite and $30 \mathrm{ml}$ of hydrochloric acid were mixed in distilled water $(150 \mathrm{ml})$ in a flask, and the mixture was stirred and heated to reflux. Then, formaldehyde $(0.1 \mathrm{~mol}, 8.11 \mathrm{~g})$ was added into the mixture dropwise, and refluxed for $4 \mathrm{~h}$. Afterwards, $\mathrm{H}_{3} \mathrm{PO}_{3}(0.12 \mathrm{~mol}, 9.84 \mathrm{~g})$ was added into the mixture, and formaldehyde $(0.12 \mathrm{~mol}, 9.73 \mathrm{~g})$ was added dropwise, then the mixture was reflux for another $3 \mathrm{~h}$. The $\mathrm{pH}$ of the mixture was adjusted to neutral with ammonia water after cooling to room temperature, and then concentrated with rotary evaporator. Finally, the solid product was washed with isopropyl alcohol for 3 times, dried at $60^{\circ} \mathrm{C}$, the novel flame retardants, CADP, was obtained. The synthesis route is shown in Fig. 1.

Pretreatment of cotton fabrics

Before the modification with CADP, cotton fabrics were treated with sodium hydroxide. Cotton fabrics were soaked in sodium hydroxide solutions $(20 \% \mathrm{w} / \mathrm{w})$ for $5 \mathrm{~min}$. Then the cotton fabrics were washed with distilled water to neutral and dried at $60^{\circ} \mathrm{C}$ to prepare pretreated cotton (D-cellulose).

Flame-retardant treatment of cotton fabrics

Different concentrations of CADP solutions were prepared, and 5\% dicyandiamide were dissolved in these solutions as catalyst. Then D-cellulose were soaked in these CADP solutions with a bath ration of 1:20 for 10 min at $90^{\circ} \mathrm{C}$. After soaking, cotton fabrics were rolled to achieve a liquid rate of $120 \%$. The cotton fabrics were cured at $185^{\circ} \mathrm{C}$ in a baking machine for $5 \mathrm{~min}$, and the flame-retardant cotton fabrics (CADPcotton) were prepared after washed and dried. The reaction between during treatment is shown in Fig. 2 .

\section{Characterization}

Fourier transform infrared (FTIR) of CADP and cotton fabrics were recorded on a Spectrum GX spectrometer (Perkin-Elmer, Waltham, MA, USA) at a range from 400 to $4000 \mathrm{~cm}^{-1}$, and the resolution was $4 \mathrm{~cm}^{-1}$.

Thermogravimetric (TG) analysis was carried out on a Pyris 1 thermogravimetric analyzer (Perkin-Elmer) in either a nitrogen or an air atmosphere. The samples were heated from 40 to $700^{\circ} \mathrm{C}$ with a speed of 10 ${ }^{\circ} \mathrm{C} / \mathrm{min}$ and a flow rate of $60 \mathrm{ml} / \mathrm{min}$.

The add-ons were calculated using the following formula: 
Add - on $(\%)=\frac{w_{1}-w_{0}}{w_{0}} \times 100 \%$

Where $W_{0}$ are the weight of the pure cotton fabrics, $W_{1}$ are the weights of CADP-cotton.

Limiting oxygen index (LOI) was tested on a M606B digital display oxygen index tester instrument (Qingdao Shanfang Instrument Co. Ltd., Qingdao, China) according to ASTM D2863-2000.

The vertical burning tests were measured on a YG815B vertical fabric flame-retardant tester (Nantong Sansi Electromechanical Science \& Technology Co. Ltd., Qidong, China) according to ASTM D6413-99.

The durability of CADP-cotton against gentle hand washes and home machine washes was measured according to AATCC 61-2006: test No. 1A and No. 2A, using a color fastness tester (Roaches International Ltd., Birstall, UK). In test No. $1 \mathrm{~A}$, solution of WOB $(0.37 \% \mathrm{w} / \mathrm{w})$ and 10 steel balls were added into the stainless steel canisters, and fabrics were washed for $45 \mathrm{~min}$ at $40{ }^{\circ} \mathrm{C}$, which was considered to be 5 laundering cycles (LCs) of gentle hand washes. In test No. 2A, solution of WOB standard reference detergent $(0.15 \% \mathrm{w} / \mathrm{w})$ and 50 steel balls were added into the stainless steel canisters, and fabrics were washed for $45 \mathrm{~min}$ at $49^{\circ} \mathrm{C}$, which was considered to be $5 \mathrm{LCs}$ of home machine washes.

Microcalorimetry tests were carried out by using a FTT0001 microcalorimeter (Fire Testing Technology Ltd., East Grinstead, UK) from 40 to $700{ }^{\circ} \mathrm{C}$ with a heating rate of $1{ }^{\circ} \mathrm{C} / \mathrm{s}$.

TG-FTIR were analysis on a Nicolet 6700 FTIR spectrometer (Thermo Fisher Scientific., Waltham, MA, US) and a Pyris $1 \mathrm{TG}$ analyzer. The samples were heated from 40 to $700^{\circ} \mathrm{C}$ at a speed of $10{ }^{\circ} \mathrm{C} / \mathrm{min}$ and a flow rate of $60 \mathrm{ml} / \mathrm{min}$ in a nitrogen atmosphere. FTIR was recorded at a range from 400 to $4000 \mathrm{~cm}^{-1}$ with a resolution of $4 \mathrm{~cm}^{-1}$.

Scanning electron microscopy (SEM) were carried out on a Phenom ProX desktop scanning electron microscope (Phenom-World BV., Eindhoven, Netherlands), and the acceleration voltage was $20 \mathrm{kV}$. And the elemental compositions were measured by energy-dispersive X-ray spectroscopy (EDS).

Whiteness was evaluated according to AATCC 110-2000 on a Datacolor 650 spectrophotometer (Datacolor Inc., Lawrenceville, NJ, USA).

The tensile tests were performed by an electromechanical universal testing machine (MTS Systema Corp., Eden Prairie, MN, USA) according to ASTM 5035-2006.

The skin irritations of cotton fabrics were carried out on 3D skin model by reconstruct the in vitro test method of human epidermis model. Cotton fabrics were put into the sterilization box and sterilized at 121 ${ }^{\circ} \mathrm{C}$ for $20 \mathrm{~min}$. Then the extract was immersed in DMEM medium containing 10\% serum at the ratio of 6 $\mathrm{cm}^{2} / \mathrm{ml}$ and extracted at $37{ }^{\circ} \mathrm{C}$ for $24 \mathrm{~h}$ after filtration. After that, $25 \mu \mathrm{l}$ extract drops were absorbed and added to the tissue surface of the 3D epidermal model, and three epidermal models were repeated in each group. After $30 \mathrm{~min}$ at room temperature, the models were washed with sterile DPBS buffer one by one. 
Then, the models were cultured in the incubator for $42 \mathrm{~h}$, and the relative tissue viability of each sample was determined by MTT tissue viability test.

\section{Results And Discussion}

\section{FTIR and TG analysis of CADP}

The FTIR spectrum of CADP is shown in Fig. 3 (a). From the result, CADP showed characteristic peaks around $3425 \mathrm{~cm}^{-1}$ attributable to the N-H bond. Intense peaks appeared around 3192 and $1401 \mathrm{~cm}^{-1}$ corresponding to stretching and scissoring vibration of $\mathrm{NH}_{4}{ }^{+}$. The peak at $1702 \mathrm{~cm}^{-1}$ was assigned to the stretching vibration of $\mathrm{C}=0$ from $-\mathrm{COOH}$. Peaks at 1667 and $1543 \mathrm{~cm}^{-1}$ were belonged to the stretching vibration of amide $\Downarrow$ and amide $\varangle$. Peaks at 1225 and $990 \mathrm{~cm}^{-1}$ were assigned to the absorptions of $P=0$ and $-\mathrm{P}(=0)-\mathrm{O}-\mathrm{C}$ groups. In addition, the peak at $1069 \mathrm{~cm}^{-1}$ corresponded to stretching vibration absorption of C-N. The results suggested that CADP was synthesized.

TG analysis of CADP was carried out in nitrogen, and the curves are illustrated in Fig. 3 (b). There were three main stages in the pyrolysis of CADP. The first stage was from $100^{\circ} \mathrm{C}$ to $220^{\circ} \mathrm{C}$, which caused by the decomposition of CADP to release $\mathrm{NH}_{3}$, and the phosphonic acids were formed. In the second stage, CADP continued to decompose to form phosphonic acids when the temperature exceeded $220^{\circ} \mathrm{C}$. In the third stage $\left(400-550^{\circ} \mathrm{C}\right)$, the further dehydration and cross-linking of the phosphonic acids were occurred to form polyphosphoric acid, metaphosphate and char, etc.

Flame retardancy and durability

Flame retardant property and durability of cotton fabrics were tested by LOI measurement, vertical burning and microcalorimetry tests.

Fig. 4 shows the LOI results of control cotton fabric, CAPD-cotton, and CADP-cotton after gentle hand washes and home machine washes. The LOI value of control cotton fabric was only $17.4 \%$, making them highly flammable. After treated with CADP, the flame retardant property of cotton fabrics was remarkably enhanced, the LOI values improved with the increase of CADP concentrations. The LOI value of cotton fabric increased to $31.7 \%$ when the concentration of CADP was $10 \%$, and it reached $41.6 \%$ when the concentration of CADP increased to $40 \%$. After launder cycles (LCs), the LOI values of CADP-cotton decreased. And the more launder cycles and more intense of washing conditions, the more significant LOI value decreased. However, flame retardant property of treated cotton fabrics still maintained very well. The LOI value of $40 \%$ CADP-cotton remained at $30.2 \%$ and $26.4 \%$ after 50 LCs of gentle hand washes and home machine washes, respectively. After washing process, 40\% CADP-cotton still reached the flame retardant standard LOI value of cotton fabric (> 26\%) (Abou-Okeil, El-Sawy \& Abdel-Mohdy, 2013).

Fig. 5 shows the images of control and treated cotton fabrics during vertical burning tests, the corresponding results of vertical burning tests and micro calorimetry are shown in Table 1. During vertical burning tests, control cotton fabric was quickly ignited and burned vigorously until the sample burned to 
ashes. The after-flame and after-glow times were 6 and $5 \mathrm{~s}$, respectively. By contrast, 40\% CADP-cotton did not ignite during the test, and $69 \mathrm{~mm}$ of intact char was left in the ignition area. And 40\% CADP-cotton after 50 LCs of home machine washes also did not ignite in air. No after-flame and after-glow were observed, and $93 \mathrm{~mm}$ of char was formed in the ignition area. In addition, the peak of heat release rate (pHRR) of CADP-cotton decreased significantly from $290.6 \mathrm{~W} / \mathrm{g}$ to $36.2 \mathrm{~W} / \mathrm{g}$. Flame retardant property of CADP-cotton decreased slightly after 50 LCs of home machine washes, and the pHRR of $40 \%$ CADPcotton increased to $40.3 \mathrm{~W} / \mathrm{g}$.

The results indicated that CADP could significantly improve the flame retardant property of cotton fabrics. By forming covalent bond with cellulose, CADP could firmly grafted to cellulose, and the cotton fabrics with high and durable flame retardant property were prepared, which still well preserved after 50 LCs of home machine washes.

Table 1 The results of the vertical burning test and microcalorimetry test

\begin{tabular}{|lllllc|}
\hline Samples & $\begin{array}{l}\text { Add-on } \\
(\%)\end{array}$ & $\begin{array}{l}\text { After-flame } \\
\text { time (s) }\end{array}$ & $\begin{array}{l}\text { After-glow } \\
\text { time (s) }\end{array}$ & $\begin{array}{l}\text { Char } \\
\text { length } \\
(\mathrm{mm})\end{array}$ & $\begin{array}{c}\text { pHRR } \\
(\mathrm{W} / \mathrm{g})\end{array}$ \\
\hline Control cotton & - & $6 \pm 2$ & $5 \pm 1$ & - & 290.6 \\
\hline CADP-cotton & $26.9 \pm 0.4$ & $0.0 \pm 0.0$ & $0.0 \pm 0.0$ & $69 \pm 3$ & 36.2 \\
\hline $\begin{array}{l}\text { CADP-cotton after 50 LCs of home } \\
\text { machine washes }\end{array}$ & $21.6 \pm 0.4$ & $0.0 \pm 0.0$ & $0.0 \pm 0.0$ & $93 \pm 4$ & 40.3 \\
\hline
\end{tabular}

Characterization of cotton fabrics

The effects of CADP on the structure of cotton fabric and laundering cycles on the structure of CADPcotton were studied by FTIR analysis, Fig. 6 shows the FTIR spectra. For control cotton fabric, the peak presented at $3375 \mathrm{~cm}^{-1}$ was allocated to stretching vibration of $\mathrm{O}-\mathrm{H}$, peaks at 2905 and $1366 \mathrm{~cm}^{-1}$ were identified as C-H stretching vibration and deformation vibration, peaks shown at 1162, 1111 and 1060 $\mathrm{cm}^{-1}$ were associated with the adsorption band of $\mathrm{C}-\mathrm{O}-\mathrm{C}$. It was observed that some new peaks presented in CADP-cotton. The peaks at 3169 and $1401 \mathrm{~cm}^{-1}$ were identified as $\mathrm{NH}_{4}{ }^{+}$stretching and scissoring vibration, which belonged to the unreacted $-\mathrm{P}=\mathrm{O}\left(\mathrm{ONH}_{4}^{-}\right)_{2}$ groups on CADP-cotton. The peaks at 1225 and $991 \mathrm{~cm}^{-1}$ were associated to the absorption of $\mathrm{P}=0$ and $\mathrm{P}(=0)-\mathrm{O}-\mathrm{C}$, indicating the existence of CADP on cellulose. From Fig. 6, the FTIR spectrum of CADP-cotton after 50 LCs of home machine washes was almost the same as the spectrum of CADP-cotton before washing. However, the peaks of $\mathrm{NH}_{4}{ }^{+}$(3169 and $\left.1401 \mathrm{~cm}^{-1}\right)$ were clearly weakened, suggesting the reduction of the unreacted $-\mathrm{P}=\mathrm{O}\left(\mathrm{O}^{-}\right.$ $\left.\mathrm{NH}_{4}{ }^{+}\right)_{2}$ reactive groups after washing process.

SEM and EDS analysis 
To explore the influence of washing process on CADP-cotton, SEM and EDS of cotton fabric, $40 \%$ CADPcotton, 40\% CADP-cotton after home machine washes and 40\% CADP-cotton after burning were carried out. Fig. 7 shows the SEM images, and the chemical compositions of cotton fabrics are listed in Table 2.

Cotton fibers (Fig. 7 (a) and (b)) were slightly crimped with some grooves on the surface, free of any other materials, and the fibers consisted of $50.26 \% \mathrm{C}$ and $49.72 \% \mathrm{O}$. Compared with control cotton fabric, the surface morphology and chemical compositions of CADP-cotton were changed. After the treatment with CADP, the fibers were slightly swollen, and a large amount of substances were observed (Fig. 7 (c) and (d)). Besides, $12.78 \% \mathrm{P}$ and 1.60 of $\mathrm{N}$ were found in CADP-cotton. After $50 \mathrm{LCs}$ of home machine washes, the fibers were still covered with a large amount of flame retardants (Fig. 7 (e) and (f)), indicating that CADP was indeed firmly grafted onto fibers. During the modification, $-\mathrm{P}=\mathrm{O}\left(\mathrm{O}^{-} \mathrm{NH}_{4}{ }^{+}\right)_{2}$ reactive groups of CADP reacted with the $\mathrm{C} 6-\mathrm{OH}$ of cellulose, then the formation of $-\mathrm{P}(=0)-\mathrm{O}-\mathrm{C}$ bonds allowed CADP to be firmly grafted on cellulose. However, $0.79 \% \mathrm{Na}$ appeared in CADP-cotton after home machine washes, while the content of $\mathrm{N}$ decreased to $9.75 \%$, content of $\mathrm{P}$ remained at $1.76 \%$.

The results of FTIR, EDS and SEM indicated that CADP was firmly grafted onto cellulose. But there were some unreacted $-\mathrm{P}=\mathrm{O}\left(\mathrm{O}^{-} \mathrm{NH}_{4}^{+}\right)_{2}$ groups on CADP-cotton, which reacted with the $\mathrm{Na}^{+}$in the washing liquid to form $-\mathrm{P}=\mathrm{O}\left(\mathrm{O}^{-} \mathrm{Na}^{+}\right)_{2}$ during washing. During combustion, $-\mathrm{P}=\mathrm{O}\left(\mathrm{O}^{-} \mathrm{NH}_{4}{ }^{+}\right)_{2}$ could form phosphonic acids to promote the dehydration of cellulose, while $-\mathrm{P}=\mathrm{O}\left(\mathrm{O}^{-} \mathrm{Na}^{+}\right)_{2}$ could not. The more unreacted $-\mathrm{P}=\mathrm{O}\left(\mathrm{O}^{-}\right.$ $\left.\mathrm{NH}_{4}{ }^{+}\right)_{2}$ on CADP-cotton, the more $-\mathrm{P}=\mathrm{O}\left(\mathrm{ONa}^{-}\right)_{2}$ were formed during washing, and the more significant the flame retardant property of CADP-cotton was reduced. In this study, $-\mathrm{P}(=0)-\mathrm{O}-\mathrm{C}$ were introduced into casein with dimethyl phosphite, and then $-\mathrm{P}=\mathrm{O}\left(\mathrm{O}^{-} \mathrm{NH}_{4}{ }^{+}\right)_{2}$ were introduced to form CADP. There was only a small amount of unreacted $-\mathrm{P}=\mathrm{O}\left(\mathrm{O}^{-} \mathrm{NH}_{4}^{+}\right)_{2}$ on CADP-cotton, so CADP-cotton had excellent durability and could withstand up to $50 \mathrm{LCs}$ of home machine washes.

After burning, CADP-cotton formed a large amount of char (Fig. 7 (g) and (h)), which still retained the shape of the fibers, indicating the high efficiency of CADP in catalytic char formation of cellulose. Besides, some bubbles were observed on the surface of the char, and there were $2.40 \% \mathrm{P}$ and $5.32 \% \mathrm{~N}$ in the char of CADP-cotton.

Table 2 The chemical compositions of control cotton fabric, 40\% CADP-cotton and 40\% CADP-cotton after 50 LCs

\begin{tabular}{|llllll|}
\hline Samples & C & O & N & P & Na \\
\hline Control cotton fabric & 50.26 & 49.74 & - & - & - \\
\hline CADP-cotton & 41.72 & 43.90 & 12.78 & 1.60 & - \\
\hline CADP-cotton after 50 LCs of home machine washes & 41.70 & 46.00 & 9.75 & 1.76 & 0.79 \\
\hline CADP-cotton after burning & 65.10 & 27.18 & 5.32 & 2.40 & - \\
\hline
\end{tabular}


TG analysis

Fig. 8 shows TG and DTG curves of control cotton fabric, CADP-cotton and CADP-cotton after washing, and the corresponding data is also marked in Fig. 8.

Fig. 8 (a) and (b) show TG and DTG curves of cotton fabrics in nitrogen atmosphere. For control cotton fabric, the dehydration reaction of cellulose was from $40^{\circ} \mathrm{C}$ to $334^{\circ} \mathrm{C}$. Then, the main thermal degradation of cellulose was from $334^{\circ} \mathrm{C}$ to $400^{\circ} \mathrm{C}$, which corresponds to the formation of flammable gases, solid residues and volatile liquids, with a maximum mass loss rate of $2.52 \% /{ }^{\circ} \mathrm{C}$ at $362{ }^{\circ} \mathrm{C}$. When the temperature reached $600{ }^{\circ} \mathrm{C}$, only $9.25 \%$ of char yield was remained. After the modification with CADP, the charring capacity of CADP-cotton was improved significantly, and the pyrolysis process of CADP-cotton was earlier than that of control cotton fabric. CADP-cotton suffered a significant mass loss at $239^{\circ} \mathrm{C}$, because the flame retardants on cotton fabrics decomposed to release $\mathrm{NH}_{3}$, phosphorus acid and polyphosphoric acid from $100^{\circ} \mathrm{C}$ to $250^{\circ} \mathrm{C}$. Then, the phosphorus acid and polyphosphoric acid promoted cellulose dehydration to form char instead of depolymerization, resulting much more char $(42.42 \%)$ generated at $600{ }^{\circ} \mathrm{C}$. After $50 \mathrm{LCs}$ of home machine washes, some unreacted $-\mathrm{P}=\mathrm{O}\left(\mathrm{O}^{-} \mathrm{NH}_{4}{ }^{+}\right)_{2}$ groups on CADP-cotton reacted with $\mathrm{Na}^{+}$in the washing liquid to form $-\mathrm{P}=\mathrm{O}\left(\mathrm{O}^{-} \mathrm{Na}^{+}\right)_{2}$ during washing, so the phosphorus acid and/or polyphosphoric acid from CADP-cotton decreased. The pyrolysis process of CADP-cotton after washing was later than that of CADP-cotton, and the maximum mass loss rate $\left(V_{\text {max }}\right)$ decreased. However, the charring capacity of CADP-cotton after washing still maintained very well.

The results of TG and DTG analysis in air were similar to these in nitrogen. The depolymerization of control cotton fabric occurred from $320^{\circ} \mathrm{C}$ to $360^{\circ} \mathrm{C}$, and the further oxidation of the residue occurred from $450^{\circ} \mathrm{C}$ to $530^{\circ} \mathrm{C}$ in the presence of oxygen. By contrast, CADP promoted cellulose dehydration to form char before the depolymerization. The charring capacity of CADP-cotton before and after washing was improved significantly.

TG-FTIR analysis

The TG-FTIR coupling technique was carried out to identify the volatile gaseous products of control cotton fabric, CADP-cotton and CADP-cotton after washing from thermal degradation. The FIIR spectra of the gaseous products from cotton fabrics at different temperature are shown in Fig. 9.

From Fig. 9 (a), control cotton fabric depolymerized to release a large amount of volatiles from $340{ }^{\circ} \mathrm{C}$ to $360{ }^{\circ} \mathrm{C}$. The peaks at $2325 \mathrm{~cm}^{-1}$ and $3554 \mathrm{~cm}^{-1}$ were assigned to the vibration of two non-flammable gaseous: $\mathrm{CO}_{2}$ and water vapor, respectively. In addition, some flammable gaseous were observed in the volatile gaseous from control cotton fabric: the peaks at 2970 and $2910 \mathrm{~cm}^{-1}$ were allocated the hydrocarbons, the peaks at 1763 and $1064 \mathrm{~cm}^{-1}$ belonged to carbonyl compounds and ethers, respectively. After the modification by CADP, flammable gaseous products were significantly reduced. During thermal degradation, the volatile gaseous products of CADP-cotton were water vapor and $\mathrm{CO}_{2}$, and a small amount of hydrocarbons and carbonyl compounds, because CADP could promote cellulose 
dehydration to form char instead of releasing flammable gaseous. These results also validated the catalytic effect of CADP on cellulose. As shown in Fig. 9 (c), the flammable gaseous products released from CADP-cotton after $50 \mathrm{LCs}$ of home machine washes slightly increased. Besides, no phosphoruscontaining compound was observed in gaseous phase, indicating that CADP mainly played an important role in condensed phase.

Whiteness and mechanical properties of cotton fabrics

Fig. 10 shows the whiteness and tensile strength results of cotton fabrics. During the modification, $\mathrm{P}=\mathrm{O}(\mathrm{OH})$ groups released from $\mathrm{CADP}$ could react with $-\mathrm{OH}$ of cellulose, which reduced the whiteness and tensile strength of cotton fabrics. From the results, the whiteness and tensile strength of cotton fabrics slightly decreased after modification with CADP, but they still retained well. In this study, $-P(=0)-0-C$ were introduced into casein with dimethyl phosphite, and then $-\mathrm{P}=\mathrm{O}\left(\mathrm{O}^{-} \mathrm{NH}_{4}{ }^{+}\right)_{2}$ were introduced to form CADP, making CADP more neutral to retain better tensile strength and whiteness for cotton fabric.

Skin irritation of cotton fabrics

The 3D skin model was used to investigate the skin irritations of control cotton fabric and 40\% CADPcotton, and the results are presented in Table 3. As shown in Table 3, the extracts of control cotton fabric and CADP-cotton had little influence on the tissue activity of the epidermal model. The relative tissue activities of control cotton fabric and CADP-cotton were $92.71 \%$ and $81.88 \%$, both of which were more than $50 \%$, indicating that neither control cotton fabric nor CADP-cotton had skin irritation.

Table 3 Skin irritation test results of cotton fabrics

\begin{tabular}{|llll|}
\hline Samples & Relative tissue activity $\varangle \% \otimes$ & Standard Deviation & Skin irritation* \\
\hline Control cotton fabric & 92.74 & 0.84 & nonirritant \\
\hline CADP-cotton & 81.65 & 4.92 & nonirritant \\
\hline
\end{tabular}

* Relative tissue activity $>50 \%$, standard deviation $\leq 18 \%$, nonirritant; relative tissue activity $\leq 50 \%$, standard deviation $\leq 18 \%$, irritant.

\section{Conclusions}

In this study, both the $-\mathrm{P}=\mathrm{O}\left(\mathrm{O}^{-} \mathrm{NH}_{4}{ }^{+}\right)_{2}$ reactive groups and $-\mathrm{P}(=\mathrm{O})-\mathrm{O}-\mathrm{C}$ groups were introduced into casein molecule to synthesize the novel P-N-containing flame retardants, CADP, for cotton fabrics. By the reaction between $-\mathrm{P}=\mathrm{O}\left(\mathrm{O}^{-} \mathrm{NH}_{4}^{+}\right)_{2}$ groups and $-\mathrm{OH}$ of cellulose during modification, CADP was firmly grafted onto cellulose, and $-\mathrm{P}(=0)-\mathrm{O}-\mathrm{C}$ - groups improved the durability of flame-retardant cotton fabrics, which could reduce the effect of soaping solution on the flame retardant property of cotton fabrics. After modification with CADP, the high-efficiency and durable flame-retardant cotton fabrics were prepared. The LOI value of CADP-cotton fabric could reach $41.6 \%$, which maintained at $26.4 \%$ after 50 times of home 
machine washes. During combustion, CADP mainly played an important role of condensed phase flame retardant to promote the dehydration of cellulose. In a word, bio-based and highly effective CADP can serve as an excellent substitute for Pyrovatex CP and Proban.

\section{Declarations}

\section{Acknowledgement}

This work was supported by the Research Foundation for Youth Scholars of Beijing Technology and Business University (Grant No. QNJJ2021-20), the Natural Science Foundation of Chongqing (Grant No. cstc2019jcyj-msxmX0412) and the National Natural Science Foundation of China (Grant No. 21905233).

\section{Conflict of interest}

The authors declare no conflict of interest.

\section{References}

Abou-Okeil A, El-Sawy SM, Abdel-Mohdy FA (2013) Flame retardant cotton fabrics treated with organophosphorus polymer. Carbohydr Polym, 92, 2293-2298.

Alongi J, Blasio AD, Cuttica F, Carosio F, Malucelli G (2014a) Bulk or surface treatments of ethylene vinyl acetate copolymers with DNA: Investigation on the flame retardant properties. Eur Polym J, 51, 112-119.

Alongi J, Carletto RA, Bosco F, Carosio F, Di Blasio A, Cuttica F, Antonucci V, Giordano M, Malucelli G (2014b) Caseins and hydrophobins as novel green flame retardants for cotton fabrics. Polym Degrad Stab, 99, 111-117.

Alongi J, Carletto RA, Di Blasio A, Carosio F, Bosco F, Malucelli G (2013a) DNA: a novel, green, natural flame retardant and suppressant for cotton. J Mater Chem A, 1, 4779-4785.

Alongi J, Carletto RA, Di Blasio A, Cuttica F, Carosio F, Bosco F, Malucelli G (2013b) Intrinsic intumescentlike flame retardant properties of DNA-treated cotton fabrics. Carbohydr Polym, 96, 296-304.

Alongi J, Di Blasio A, Milnes J, Malucelli G, Bourbigot S, Kandola B, Camino G (2015) Thermal degradation of DNA, an all-in-one natural intumescent flame retardant. Polym Degrad Stab, 113, 110-118.

Basak S, Ali SW (2016) Sustainable fire retardancy of textiles using bio-macromolecules. Polym Degrad Stab, 133, 47-64.

Basak S, Samanta KK, Chattopadhyay SK (2015) Fire retardant property of cotton fabric treated with herbal extract. J Text I, 106, 1338-1347. 
Basak S, Sammanta KK, Saxena S, Chattopadhyay SK, Narkar R, Mahangade R, Hadge GB (2015) Flame resistant cellulosic substrate using banana pseudostem sap. Pol J Chem Tech, 17, 123-133.

Bosco F, Carletto RA, Alongi J, Marmo L, Di Blasio A, Malucelli G (2013) Thermal stability and flame resistance of cotton fabrics treated with whey proteins. Carbohydr Polym, 94, 372-377.

Bosco F, Casale A, Mollea C, Terlizzi ME, Gribaudo G, Alongi J, Malucelli G (2015) DNA coatings on cotton fabrics: Effect of molecular size and pH on flame retardancy. Surf Coat Technol, 272, 86-95.

Carosio F, Di Blasio A, Alongi J, Malucelli G (2013) Green DNA-based flame retardant coatings assembled through Layer by Layer. Polymer, 54, 5148-5153.

Carosio F, Di Blasio A, Cuttica F, Alongi J, Malucelli G (2014) Flame Retardancy of Polyester and Polyester-Cotton Blends Treated with Caseins. Ind Eng Chem Res, 53, 3917-3923.

Chen Y, Wan C, Liu S, Wang P, Zhang G (2021) A novel flame retardant based on polyhydric alcohols and $\mathrm{P}-\mathrm{N}$ synergy for treatment of cotton fabrics. Cellulose, 28, 1781-1793.

Faheem S, Baheti V, Tunak M, Wiener J, Militky J (2019) Flame resistance behavior of cotton fabrics coated with bilayer assemblies of ammonium polyphosphate and casein. Cellulose, 26, 3557-3574.

Feng Y, Zhou Y, Li D, He S, Zhang F, Zhang G (2017) A plant-based reactive ammonium phytate for use as a flame-retardant for cotton fabric. Carbohydr Polym, 175, 636-644.

Horrocks AR (2011) Flame retardant challenges for textiles and fibres: New chemistry versus innovatory solutions. Polym Degrad Stab, 96, 377-392.

Isarov SA, Lee PW, Towslee JH, Hoffman KM, Davis RD, Maia JM, Pokorski JK (2016) DNA as a flame retardant additive for low-density polyethylene. Polymer, 97, 504-514.

Jia Y, Lu Y, Zhang G, Liang Y, Zhang F (2017) Facile synthesis of an eco-friendly nitrogen-phosphorus ammonium salt to enhance the durability and flame retardancy of cotton. J Mater Chem A, 5, 9970-9981.

Liu S, Chen Y, Wan C, Wang P, Zhang G (2021) A novel high durability flame retardant with phosphoric acid ester groups and a reactive ammonium phosphorus acid group for cotton fabrics. Cellulose, 28, 2479-2493.

Liu W, Chen L, Wang YZ (2012) A novel phosphorus-containing flame retardant for the formaldehyde-free treatment of cotton fabrics. Polym Degrad Stab, 97, 2487-2491.

Luo Y, Wang S, Fu X, Du X, Wang H, Zhou M, Cheng X, Du Z (2020) Fabrication of a Bio-Based Superhydrophobic and Flame-Retardant Cotton Fabric for Oil-Water Separation. Macromol Mater Eng, 2000624. 
Malucelli G, Bosco F, Alongi J, Carosio F, Di Blasio A, Mollea C, Cuttica F, Casale A (2014) Biomacromolecules as novel green flame retardant systems for textiles: an overview. RSC Adv, 4, 4602446039.

Mohamed OA, Abdel-Mohdy FA (2006) Preparation of flame-retardant leather pretreated with pyrovatex CP. J Appl Polym Sci, 99, 2039-2043.

Pei L, Gu X, Wang J (2021) Sustainable dyeing of cotton fabric with reactive dye in silicone oil emulsion for improving dye uptake and reducing wastewater. Cellulose, 28, 2537-2550.

Poon CK, Kan CW (2015) Effects of $\mathrm{TiO}_{2}$ and curing temperatures on flame retardant finishing of cotton. Carbohydr Polym, 121, 457-467.

Salmeia KA, Gaan S, Malucelli G (2016) Recent Advances for Flame Retardancy of Textiles Based on Phosphorus Chemistry. Polymers, 8, 319.

Sun C, Guo Z, Zhou M, Li X, Cai Z, Ge F (2021) Heteroatoms-doped porous carbon electrodes with threedimensional self-supporting structure derived from cotton fabric for high-performance wearable supercapacitors. J Power Sources, 482, 228934.

Wang D, Ma J, Liu J, Tian A, Fu S (2021) Intumescent flame-retardant and ultraviolet-blocking coating screen-printed on cotton fabric. Cellulose, 28, 2495-2504.

Wang W, Wang J, Wang X, Wang S, Liu X, Qi P, Li H, Sun J, Tang W, Zhang S, Gu X (2020) Improving flame retardancy and self-cleaning performance of cotton fabric via a coating of in-situ growing layered double hydroxides (LDHs) on polydopamine. Prog Org Coat, 149, 105930.

Xie K, Gao A, Zhang Y (2013) Flame retardant finishing of cotton fabric based on synergistic compounds containing boron and nitrogen. Carbohydr Polym, 98, 706-710.

Xu B, Wu X, Ma W, Qian L, Xin F, Qiu Y (2018) Synthesis and characterization of a novel organic-inorganic hybrid char-forming agent and its flame-retardant application in polypropylene composites. J Anal Appl Pyrolysis, 134, 231-242.

Xu F, Zhong L, Xu Y, Zhang C, Wang P, Zhang F, Zhang G (2019a) Synthesis of three novel amino acidsbased flame retardants with multiple reactive groups for cotton fabrics. Cellulose, 26, 7537-7552.

Xu F, Zhong L, Xu Y, Zhang C, Zhang F, Zhang G (2019b) Highly efficient flame-retardant and soft cotton fabric prepared by a novel reactive flame retardant. Cellulose, 26, 4225-4240.

Xu F, Zhong L, Zhang C, Wang P, Zhang F, Zhang G (2019c) Novel High-Efficiency Casein-Based P-NContaining Flame Retardants with Multiple Reactive Groups for Cotton Fabrics. ACS Sustain Chem Eng, 7, 13999-14008. 
Xu L, Wang W, Yu D (2017) Durable flame retardant finishing of cotton fabrics with halogen-free organophosphonate by UV photoinitiated thiol-ene click chemistry. Carbohydr Polym, 172, 275-283.

Yang Z, Wang X, Lei D, Fei B, Xin JH (2012) A durable flame retardant for cellulosic fabrics. Polym Degrad Stab, 97, 2467-2472.

Yasin S, Behary N, Curti M, Rovero G (2016) Global Consumption of Flame Retardants and Related Environmental Concerns: A Study on Possible Mechanical Recycling of Flame Retardant Textiles. Fibers, $4,16$.

Zhang C, Jiang Z, Zhu S, Zhu P (2021) Eco-friendly and efficient flame-retardant cotton fabric based on a multi-hydroxyl hyperbranched phosphoramidate. Cellulose, 28, 1857-1872.

\section{Figures}



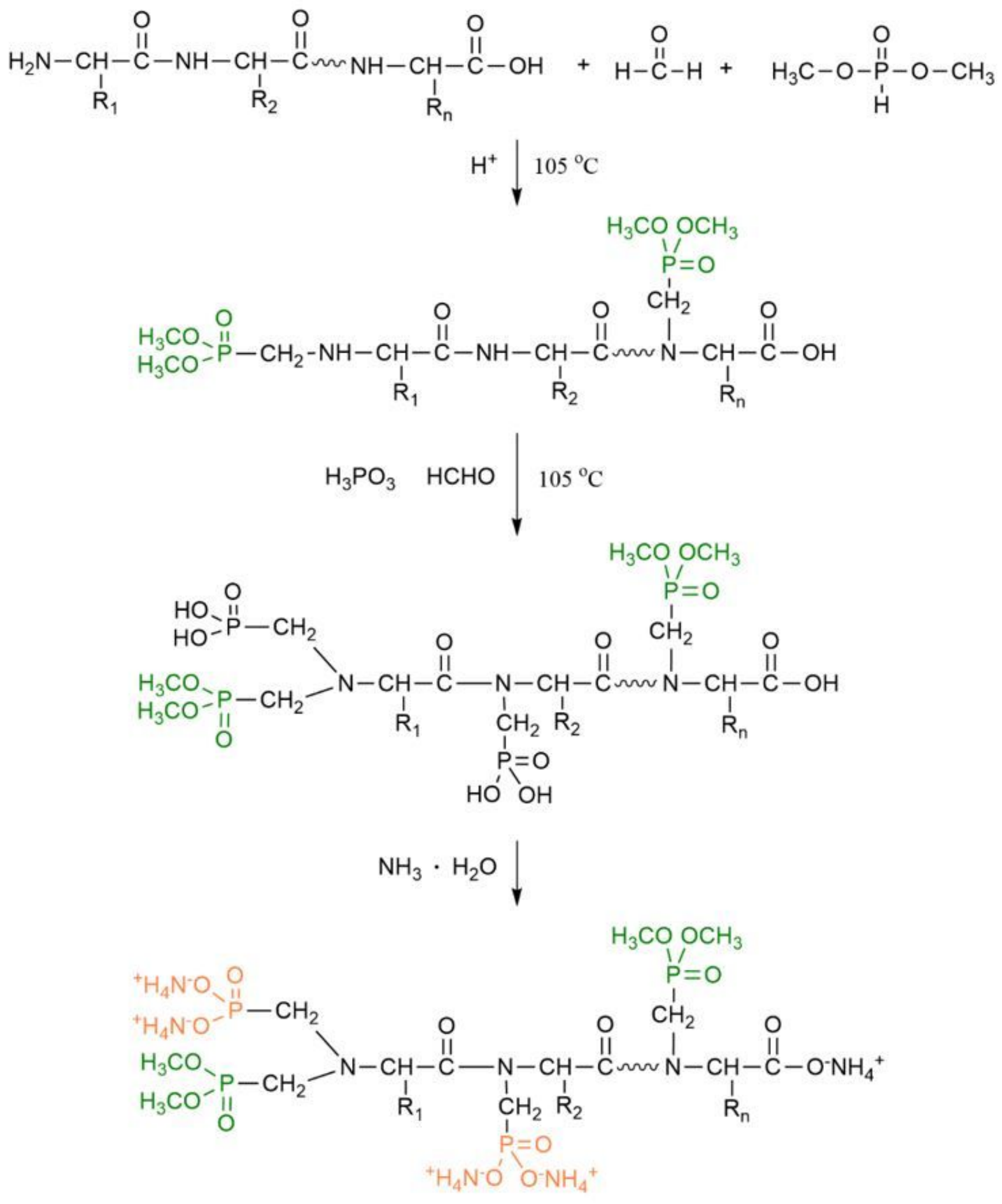

CADP

\section{Figure 1}

Synthesis route of CADP 


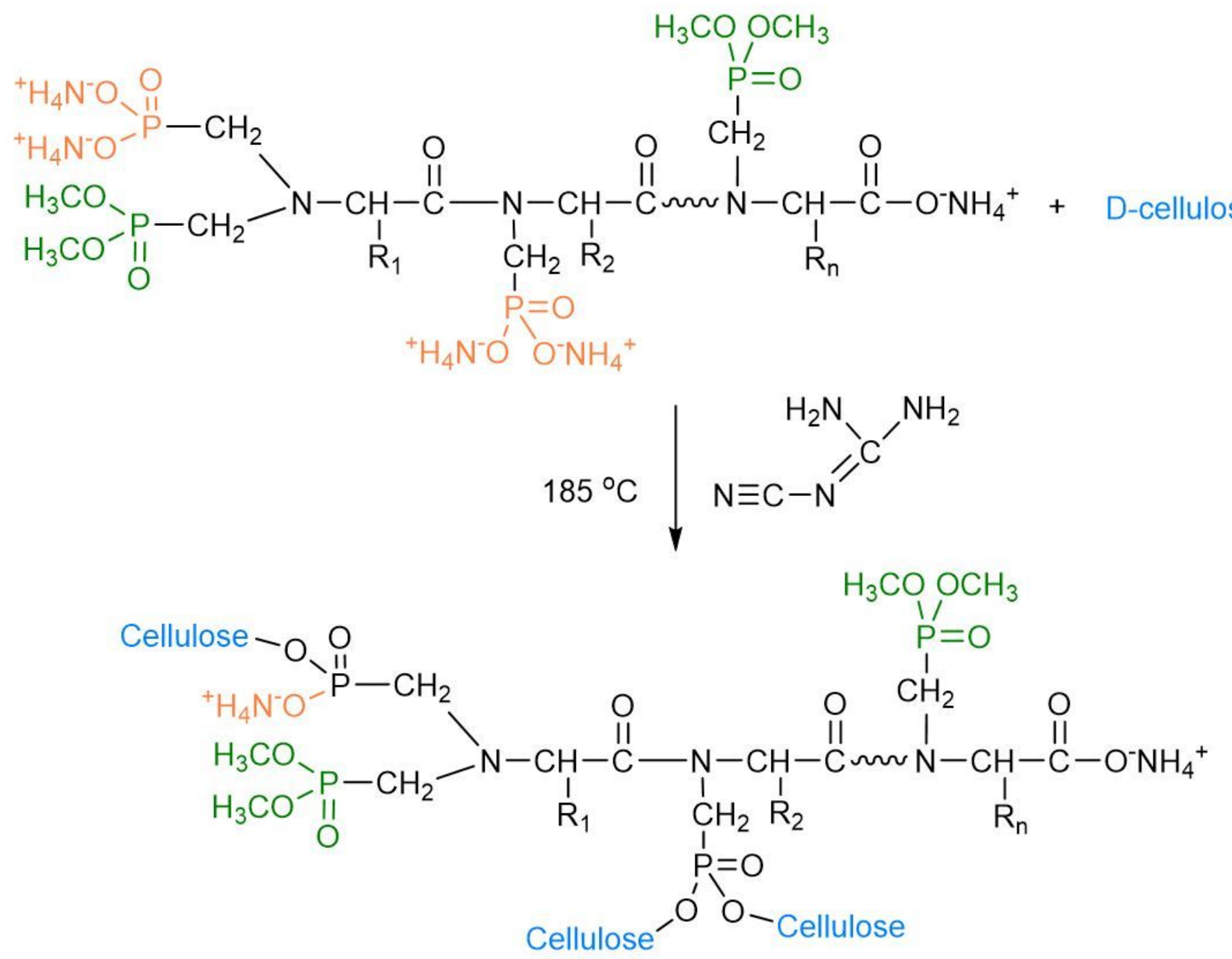

Figure 2

The reaction between CADP and D-cellulose.

(a)

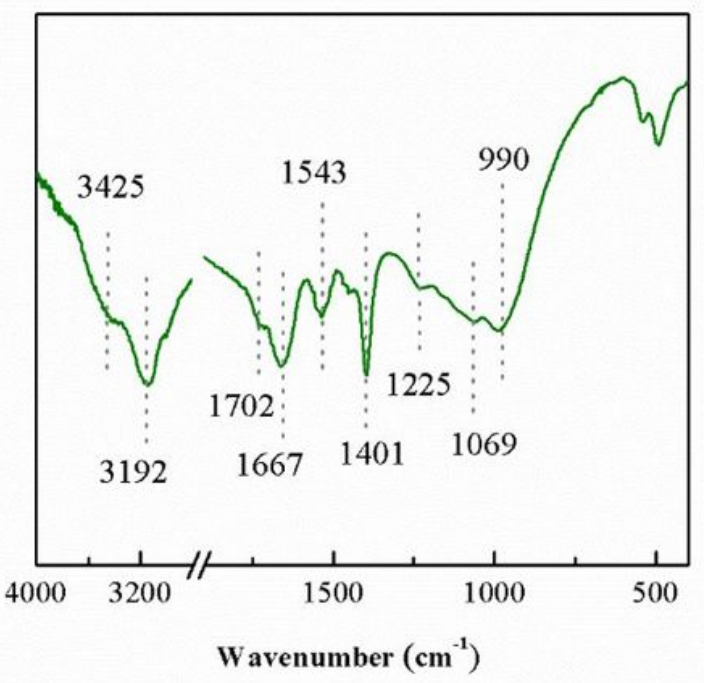

(b)

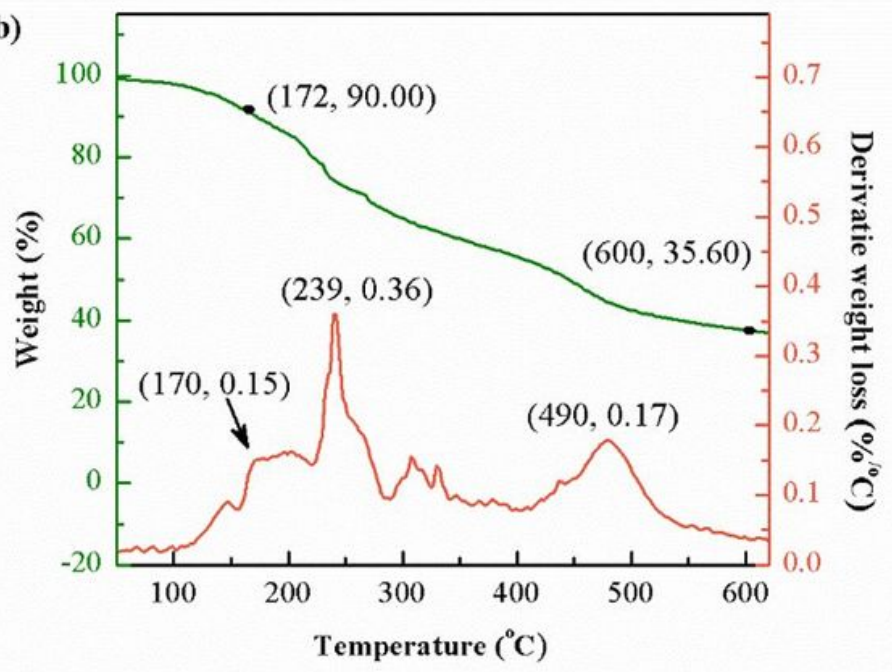


Figure 3

(a) FTIR spectrum of CADP; (b) TG and DTG curves of CADP under nitrogen atmosphere

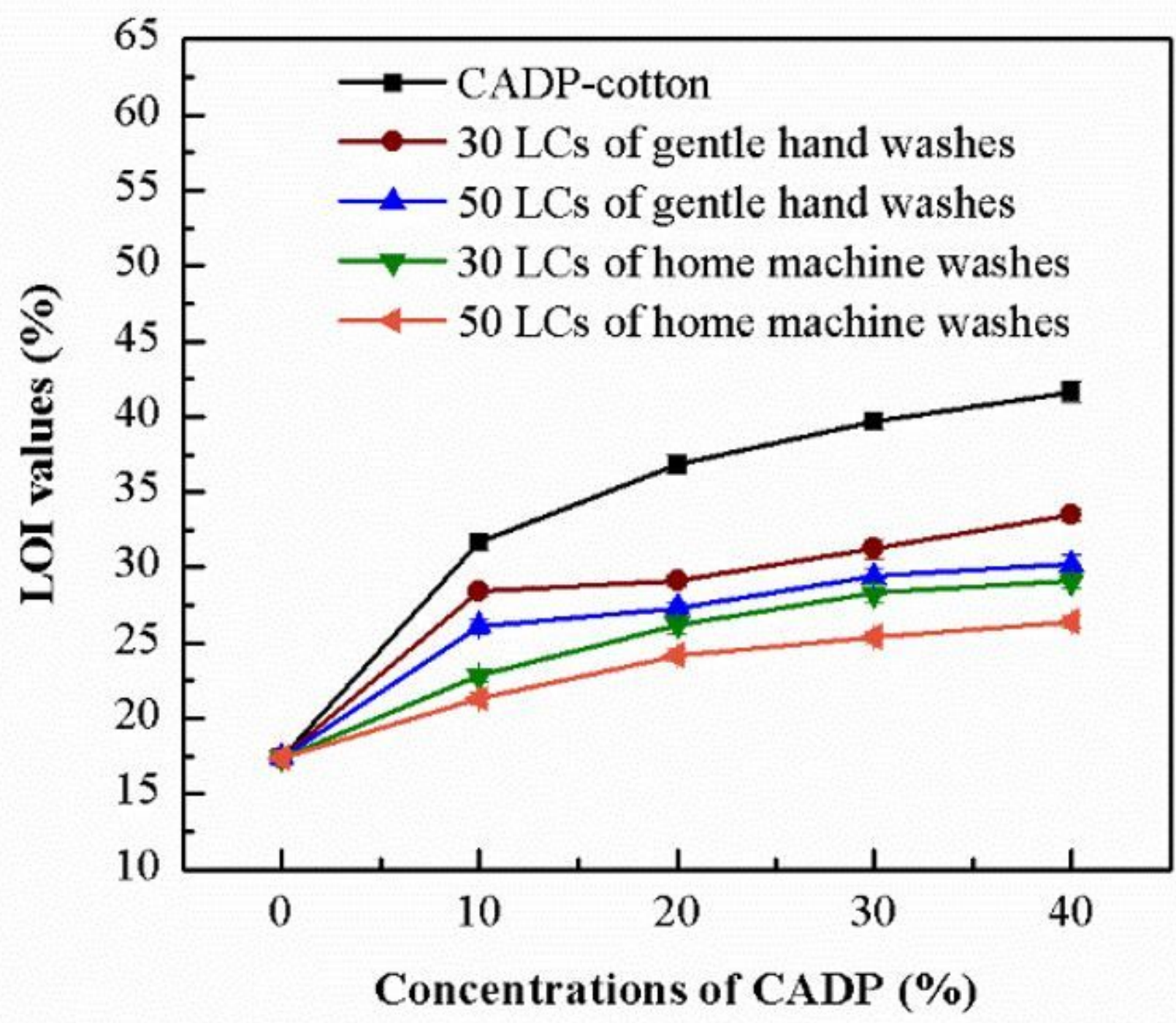

Figure 4

LOI values of cotton fabrics before and after gentle hand washes and home machine washes 


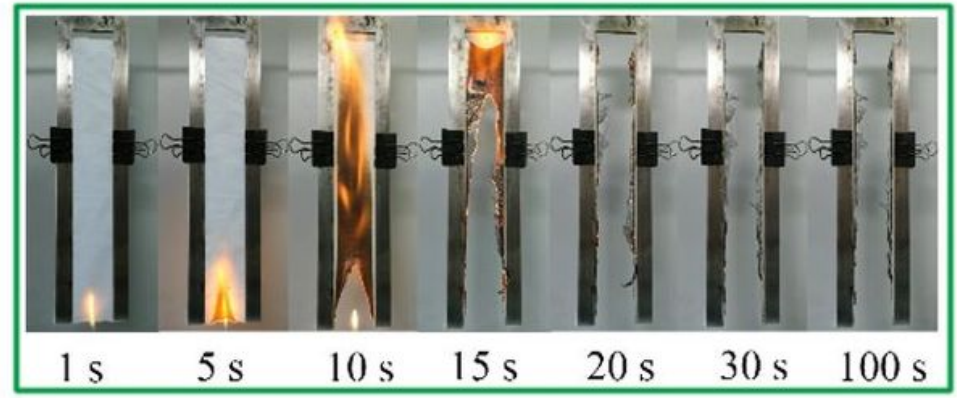

Control cotton fabric
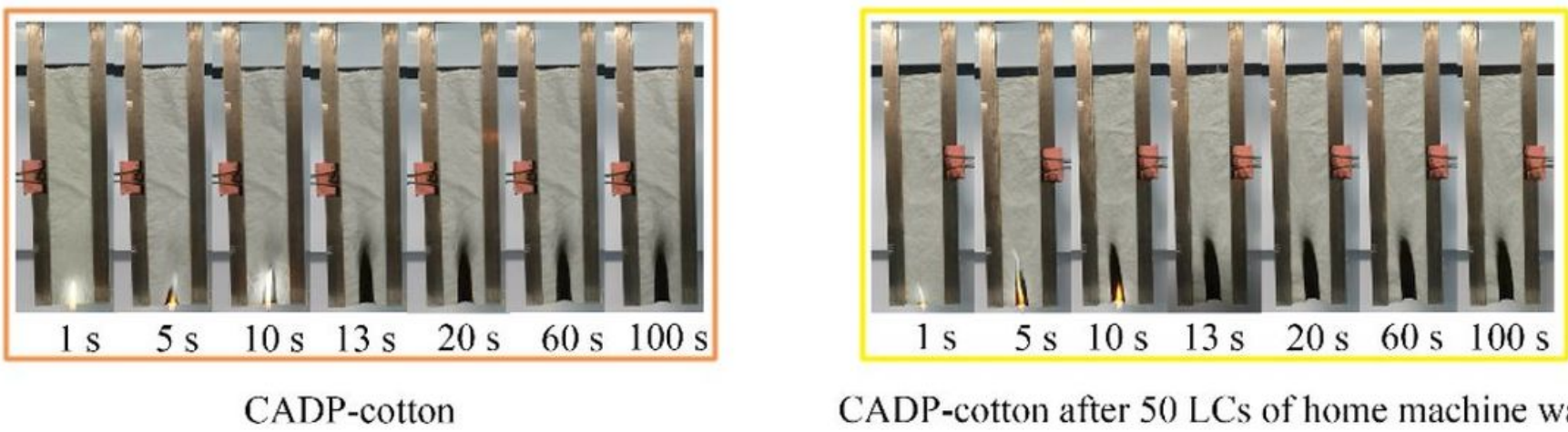

CADP-cotton after 50 LCs of home machine washes

Figure 5

Images of cotton fabrics during vertical burning tests 


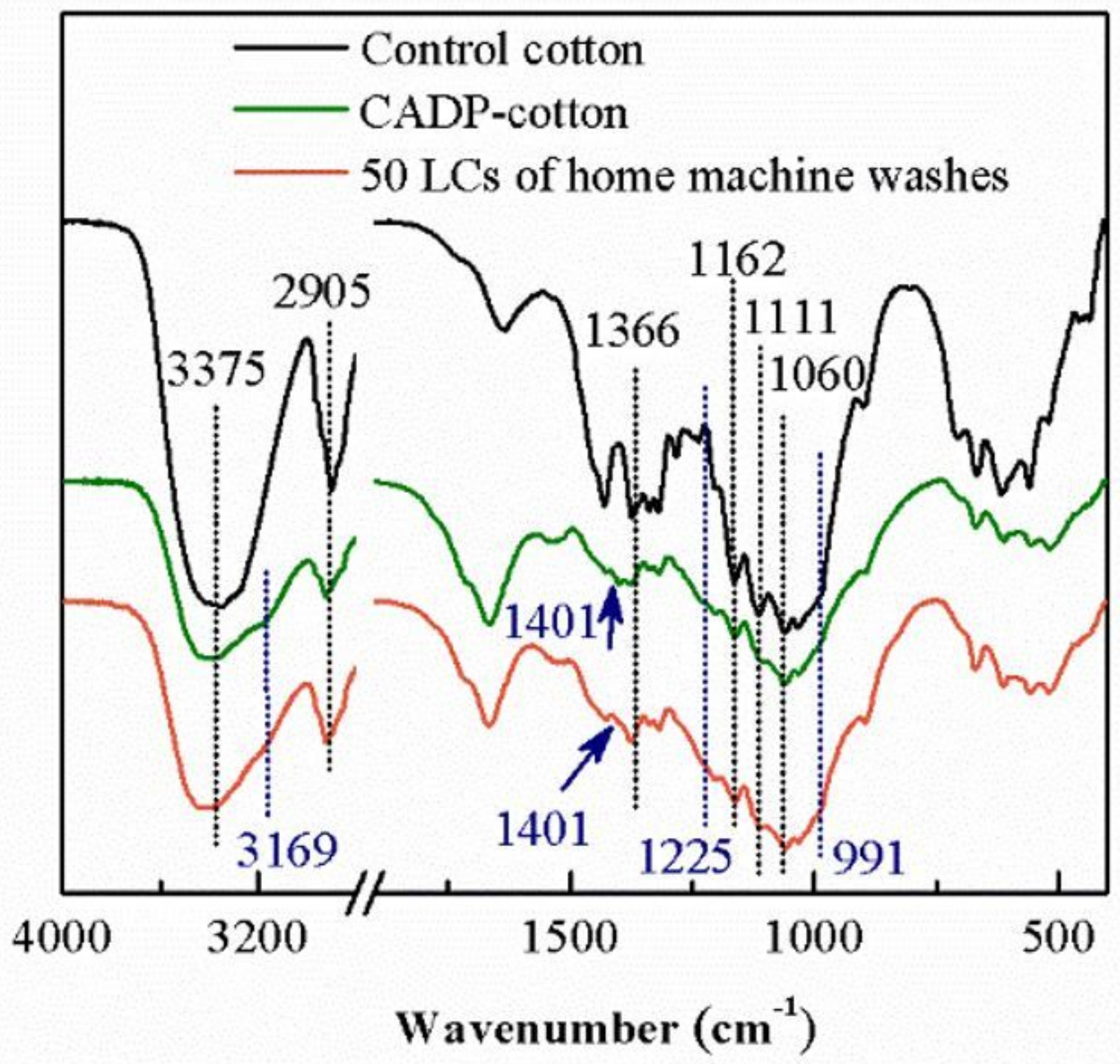

Figure 6

FTIR spectra of control cotton fabric, 40\% CADP-cotton and 40\% CADP-cotton after 50 LCs 

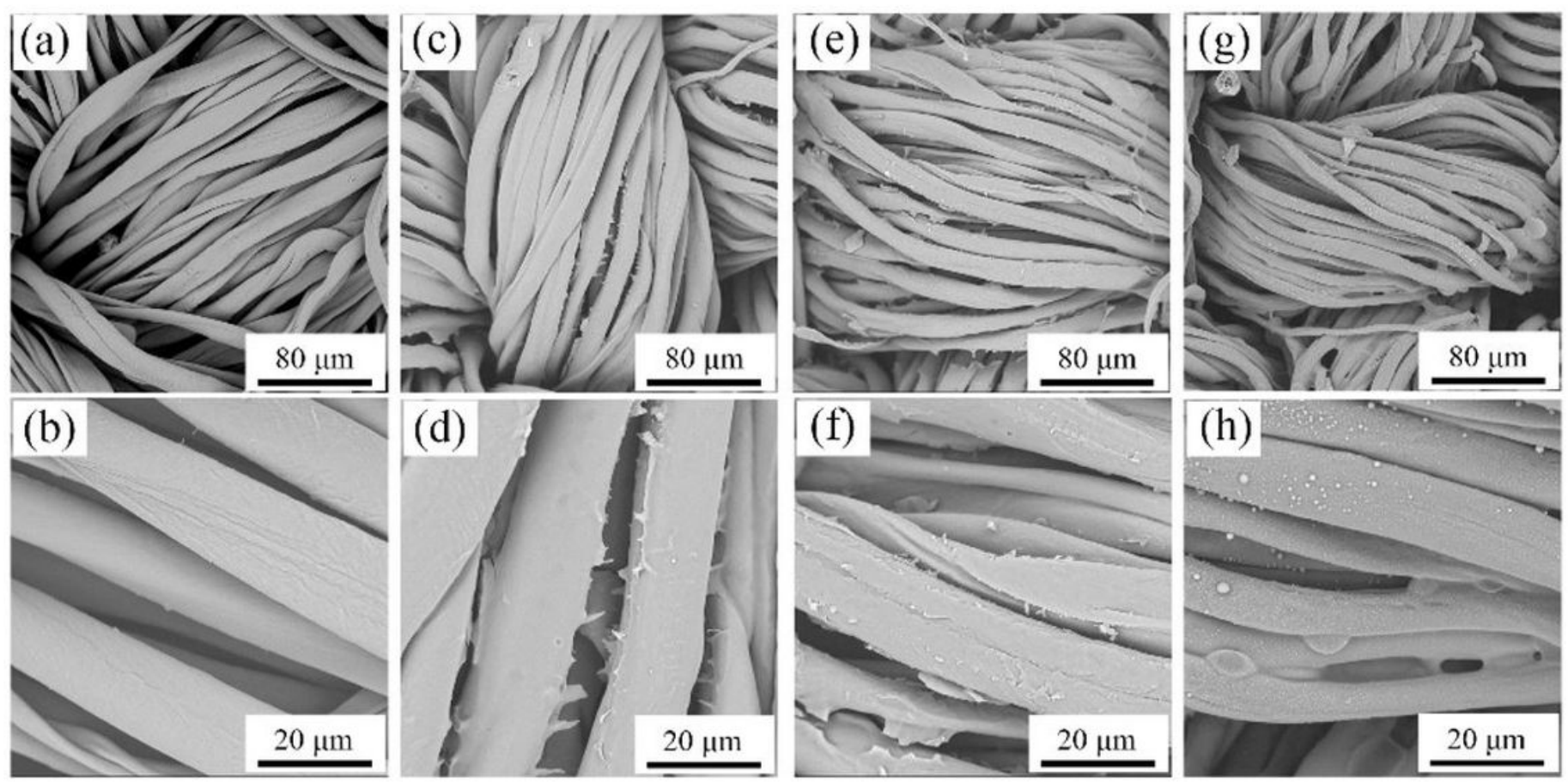

Figure 7

SEM images of control cotton fabric (a) (b); CADP-cotton (c) (d); CADP-cotton after 50 LCs of home machine washes (e) (f); CADP-cotton after burning (g) (h). Magnification times: $\times 1000$ in (a), (c), (e), (g); $\times 4000$ in (b), (d), (f), (h). 

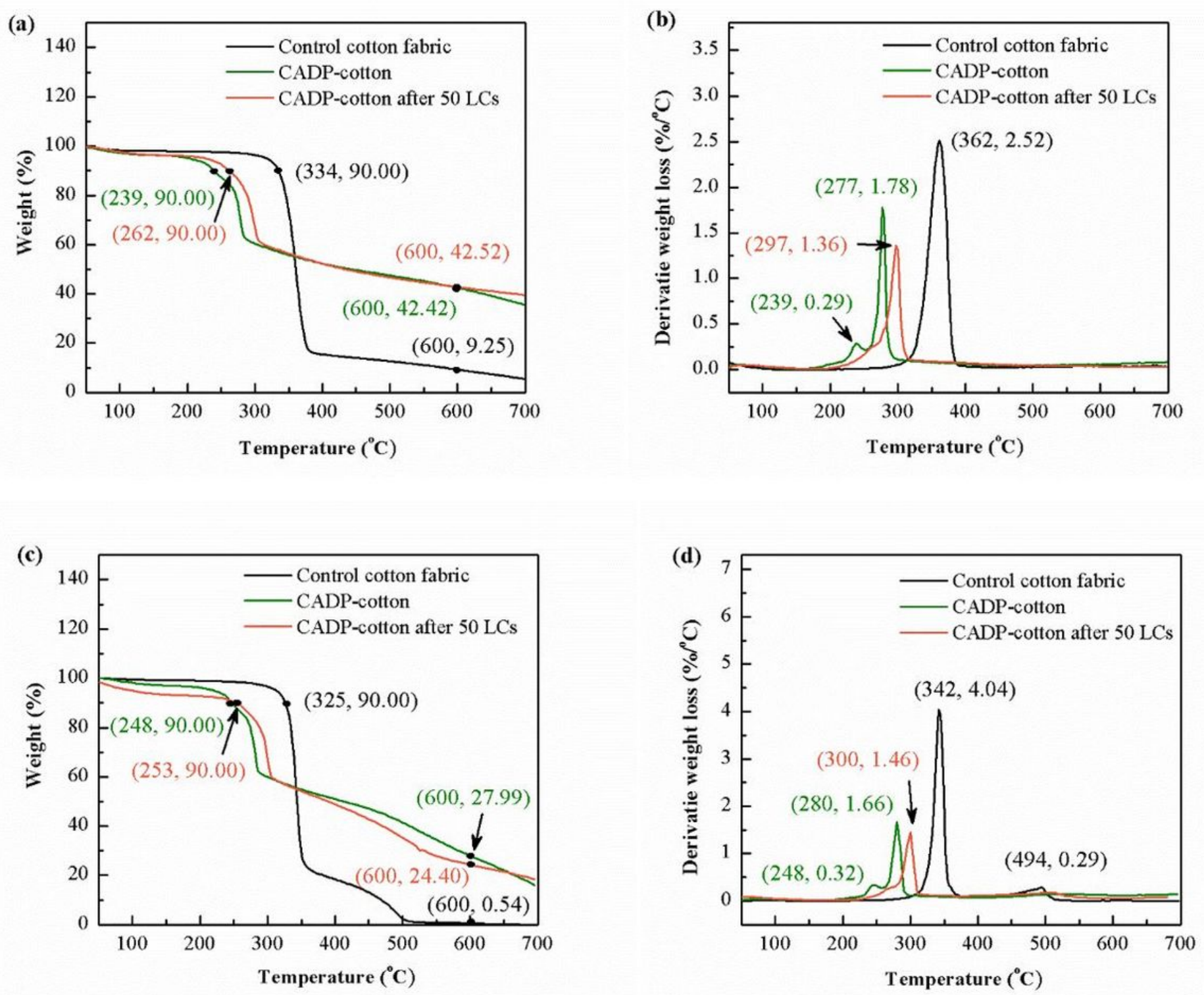

Figure 8

TG curves of control cotton fabric, CADP-cotton and CADP-cotton after 50 LCs under nitrogen atmosphere (a) and air atmosphere (c), and the DTG curves of control cotton fabric, CADP-cotton and CADP-cotton after 50 LCs under nitrogen atmosphere (b) and air atmosphere (d).
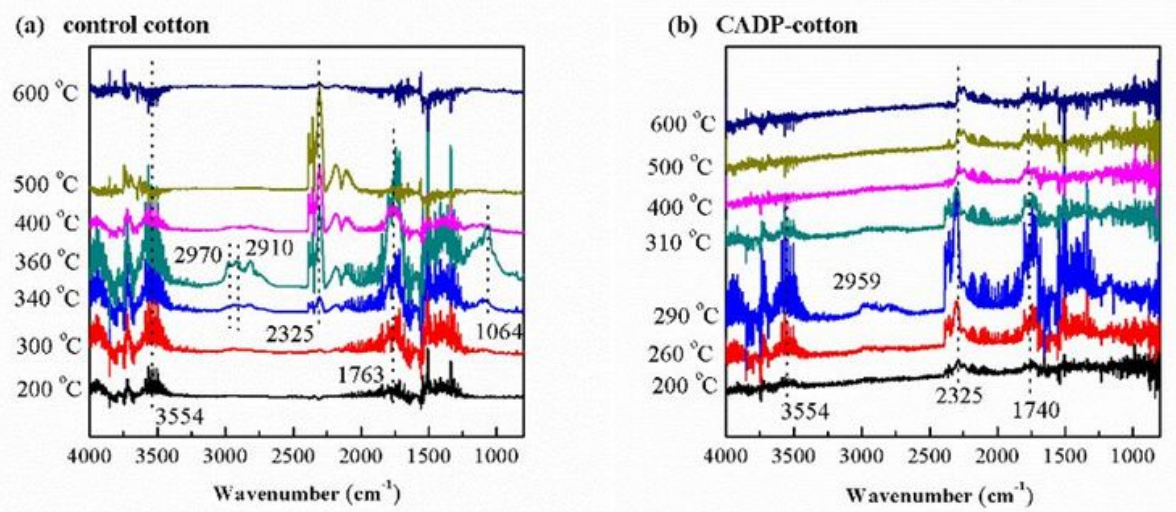

(c) CADP-cotton after $50 \mathrm{LCs}$ of home machine washes

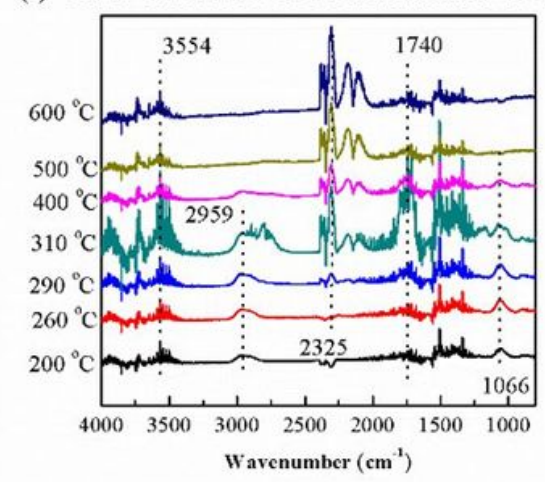




\section{Figure 9}

FTIR spectra of the volatile gases from the thermal degradation of (a) control cotton fabric, (b) CADPcotton and (c) CADP-cotton after 50 LCs of home machine washes at different temperatures.
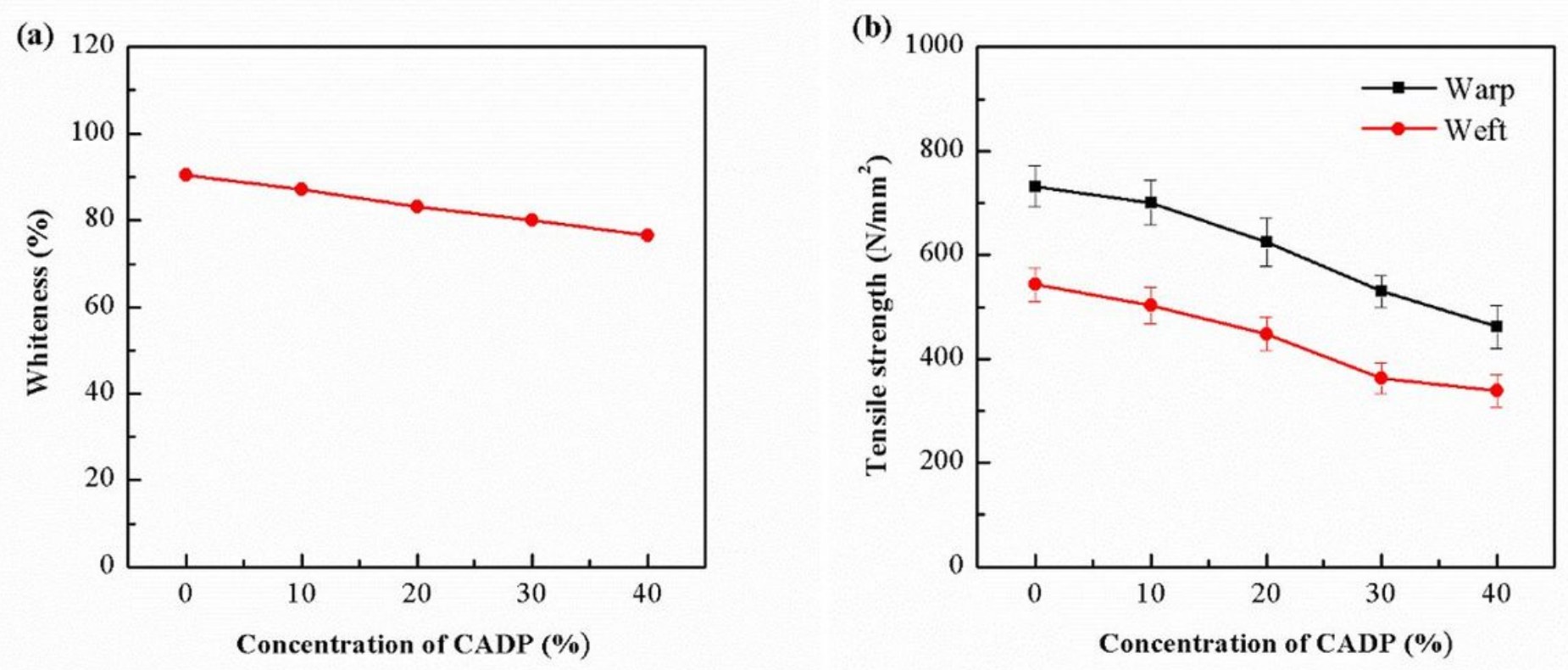

Figure 10

Whiteness (a) and tensile strength (b) of cotton fabrics treated with different concentrations of CADP

\section{Supplementary Files}

This is a list of supplementary files associated with this preprint. Click to download.

- graphicsabstract.jpg 